\title{
Phytochemical Composition, Antioxidant and Antimicrobial Activities of Ammodaucus leucotrichus Fruit From Algerian Sahara
}

\author{
ASJEL SEBAA $^{1 *}$, ABDERAZEK MAROUF ${ }^{2}$, NADIA KAMBOUCHE${ }^{1}$ and AICHA DERDOUR ${ }^{1}$ \\ 'Organic synthesis laboratory, Department of Chemistry, Faculty of Sciences, University of Oran 1 \\ Ahmed Benbella, P.B. 1524, El M'Naouer, 31000 Oran, Algeria. \\ ${ }^{2}$ Institute of Science and Technology, Department of Natural Sciences and Life, Ctr Univ Naama, \\ P.B. 66, 45000 Naama, Algeria. \\ ${ }^{*}$ Corresponding author E-mail: lamia.sebaa@yahoo.fr
}

http://dx.doi.org/10.13005/ojc/340158

(Received: October 17, 2017; Accepted: November 01, 2017)

\begin{abstract}
Ammodaucus leucotrichus Cosson \& Durieu common appellation is "Nessoufa, Moudrayga". It is an endemic plant from the family Apiaceae (Umbelliferae) frequently used by the Arab world for traditional medicine and as a food condiment. A. leucotrichus fruits have been phytochemically screened to evidence qualitative composition of secondary metabolites. Analyses assess the presence of flavonoids, tannins, saponins, coumarins, phenolic acids, alkaloids and cardiac glycosides. Antioxidant activity of different extracts is evaluated by using two methods: Ferric Reducing Antioxydant Power (FRAP) and DPPH (2, 2-diphenyl-1-picrylhydrazyl) free radical capture. Methanolic extract has a good ferric reducing capacity, superior to the capacity recorded through BHT. The capacity of trapping of free radical DPPH is interesting with an $\mathrm{IC}_{50}=2,256 \mu \mathrm{g} /$ $\mathrm{ml}$, which is similar to $\mathrm{BHA}$ with an $\mathrm{IC}_{50}=2.167 \mu \mathrm{g} / \mathrm{ml}$. The extracts and fractions are also evaluated for their antimicrobial activity against eight bacterial strains and three human pathogenic fungi, exhibiting an interesting antimicrobial profile.
\end{abstract}

Keywords: Ammodaucus leucotrichus; Fruit, Polyphenols, Antioxidant activity, Antimicrobial activity.

\section{INTRODUCTION}

The world has an endless quantity of plants used for multiple purposes. For certain plants, medicinal properties are more important than food, condiment or ornament use. Several studies assessed that therapeutic effects of certain plants are related to the presence of chemical substances such as essential oil, saponins, flavonoids and alkaloids. These metabolites are interesting because of their biological and pharmacological proprieties as well as their industrial production. 
For instance, The Algerian flora with its 3000 species belonging to several botanical families Including $15 \%$ endemic, remains very little explored on the phytochemical plan as on the pharmacological plan. The valorization of the medicinal plants of the national flora will be a great contribution to the pharmaceutical industry of Algeria and will have an economic impact certain ${ }^{1}$. Ammodaucus leucotrichus Coss. \& Dur. is from Leucotrichus subsp. and Apiaceae family is referred to as 'Kamune es sufi or akâman' in most of the ArabicAfrican countries while in Algeria, it is commonly known as "Moudrayga" and known as "Cumin chevelu" in French ${ }^{2-3}$. It is a small glabrous annual plant which Stems are locally raised, streaked and small branches shaped. Leaves are fleshy, finely divided forming flat narrow ridges. Umbels have 2 to 4 rays and involucres have very divided bracts, white flowers are positioned according to a composed umbel. Mericarps are 6-9 x 4-5 mm long with secondary ribs covered with 8 to $10 \mathrm{~mm}$ long silky hair. Hair is very dense and fuzzy, with a yellow reddish base and a white end ${ }^{4}$. The plant has a strong smell of anise. A. leucotrichus is an aromatic plant endemic of North Africa (Algeria, Morocco, Tunisia, Libya, Egypt, Mauritania and upper Niger valley) ${ }^{3-5}$. Its best implantation is in desert regions, often down a hill or a dune. In the Algerian traditional medicine, the fruits from $A$. leucotrichus are used either by the local population to the treatment of common cold, fever, vomiting, stomach ache and allergies particularly with children ${ }^{6}$. Previous phytochemical investigations on this plant are limited. Bernard et al., reported the isolation and characterization of four compounds: ammolactoneA (1), ammolactone-B (2), dihydroxy acid (3) and 3 -hydroxyperil aldehyde $(4)^{2}$. The purpose was to conduct a phytochemical and biological study concerning this plant well known in Southern Algeria for its medicinal virtues. This is why we planned to phytochemically screen different extracts and evaluate the antioxydant potential, antimicrobial.

\section{MATERIALS AND METHODS}

\section{Plant material}

The plant material consists of fruits from Ammodocus leucotrichus Coss. et al., Dur. harvested in the region of Bechar, (south of Algeria). The authentication was performed by Professor A. Marouf (Institute of Science and Technology,
Department of Natural Sciences and Life, Center University Naama, Algeria). Dried fruits were pulverized through a crusher to get a fine powder. Powder was used to prepare different extracts.

\section{Preparation of extracts}

- Powdered dried fruits (each $5 \mathrm{~g}$ ) were extracted with $50 \mathrm{ml}$ each of dimethyl ether, methanol $80 \%$, ethanol $70 \%$ and Aqueous individually, at ambient temperature, with agitation for 24-48 hours. Three extracts were obtained (EM1, EM2, EED and $\mathrm{EE}_{70 \%}$ ). The extracts were concentrated under pressure and the residues containing water were dried by lyophilisation.

- Twenty five grams of the extract ethanolic $70 \%$ were included in $200 \mathrm{ml}$ of distilled water added with lead acetate $\left[\left(\mathrm{CH}_{3} \mathrm{COO}\right)_{4} \mathrm{~Pb}\right]$ to remove chlorophyll and other low molecular weight compounds by precipitation. After filtration, the solution became red-brown. The filtrate was subjected to sequential extraction with dichloromethane, ethyl acetate and n-butanol. Thus, three obtained organics phases (DMC, AcOEt and $\mathrm{BOH}$ ) were dried by sulfate anhydrous sodium, then filtered, concentrated and dried under reduced pressure.

- $\quad$ An essential oil was obtained through an $8 \mathrm{~h}$ hydro-distillation. The distilled plant material consists of $A$. leucotrichus dried fruits. The oil was dehydrated with anhydrous sodium sulfate and stored at $4{ }^{\circ} \mathrm{C}$ in the dark.

\section{Chemical and Reagents}

Dimethyl ether, $\mathrm{CHCl}_{3}, \mathrm{CH}_{2} \mathrm{Cl}_{2}, 70 \%$ Ethanol, $80 \%$ methanol, n-butanol, ethyl acetate, (DMSO) dimethyl sulfoxide, Distilled water, (FRAP) Ferric Reducing Antioxidant Power, DPPH (2, 2diphenyl-1-picrylhydrazyl), BHT, BHA, Quercetin, Ascorbic acid, Acetic acid, formic acid, lead acetate, $\mathrm{NH}_{4} \mathrm{OH}$ Potassium hydroxide, phosphate buffer, Potassium ferricyanide, trichloroacetic, $\mathrm{SbCl}_{3}$, Fehling solution, Folin-Ciocalteu solution, Dragendorff, Komarowski, Strasny, Neu, anisaldehyde and Zimmermann reagents, TLC plates $60 \mathrm{~F}_{254}$ silica, Potassium hydroxide, Ferric chloride, Muller Hinton medium (MHI), Sabouraud medium and Sulfate anhydrous sodium were obtained from Sigma-Aldrich Chemicals and other chemicals and reagents used were of analytical grade. 


\section{Preliminary Phytochemical Analysis}

Screening was processed with chemical tests and/or chromatographic tests through $60 \mathrm{~F}_{254}$ silica TLC assays after disclosing compounds with specific reagents and after examining results through visible light and/or UV7-8. Migration systems used were:AcOEt-MeOH-H $\mathrm{H}_{2} \mathrm{O}$ (100: 13.5: 10) (Anthracenes derivatives, cardiac glycosides); AcOEt-AcOH-HCOOH- $\mathrm{H}_{2} \mathrm{O}$ (100:11:11:26) (coumarin, phenol acid, flavonoids, sesquiterpenelactones); $\mathrm{CHCl}_{3}-$ $\mathrm{MeOH}-\mathrm{H}_{2} \mathrm{O}$ (65:35:10) (saponins); $\mathrm{CH}_{2} \mathrm{Cl}_{2}-\mathrm{MeOH}$ $\mathrm{NH}_{4} \mathrm{OH}(95: 5: 0,5)$ (alkaloids); AcOEt-MeOH-H $\mathrm{H}_{2} \mathrm{O}$ (100:17:13) (quinones). For TLC plates disclosing, reagents used were: Folin-Ciocalteu (phenol acid), Reducing compounds (Fehling), Dragendorff (alkaloids), Komarowski (saponins), Neu (flavonoids), Strasny (tannins), anisaldehyde (sterols, triterpenes), Zimmermann (lactone sesquiterpenes), $\mathrm{KOH}$ (anthraquinones, coumarins, quinones), $\mathrm{SbCl}_{3}$ (cardiac glycosides).

\section{Antioxidant activity Reducing power method}

Reducing power of methanol extract of $A$. leucotrichus fruits was measured according to Yen \& Chen method ${ }^{9}$. Briefly, $1.0 \mathrm{ml}$ of different concentration sample $(0.25,0.5,0.75$ and $1.0 \mathrm{mg} /$ $\mathrm{ml}$ ) was mixed with $2.5 \mathrm{ml}$ of a $0.2 \mathrm{M}$ phosphate buffer $(\mathrm{pH} 6.6)$ and $2.5 \mathrm{ml}$ of a $1 \%(\mathrm{w} / \mathrm{v})$ solution of potassium ferricyanide. The mixture was incubated in a water bath at $50{ }^{\circ} \mathrm{C}$ for $20 \mathrm{~min}$. afterwards, $2.5 \mathrm{ml}$ of a $10 \%(\mathrm{w} / \mathrm{v})$ trichloroacetic acid solution was added and the mixture was then centrifuged at $10000 \mathrm{rpm}$ for 10 minute. A $2.5 \mathrm{ml}$ aliquot of the upper layer was combined with $2.5 \mathrm{ml}$ of distilled water and $0.5 \mathrm{ml}$ of a $0.1 \%(\mathrm{w} / \mathrm{v})$ solution of ferric chloride, and absorbance was measured at 700 $\mathrm{nm}$. BHT $(0.25,0.5,0.75$ and $1 \mathrm{mg} / \mathrm{ml}$ concentrations) was used as a positive control.

\section{DPPH method}

DPPH method was used to assess anti-free radical activity of extracts different ${ }^{10-11}$. A 6 $10^{-5} \mathrm{M}$ solution of DPPH in methanol was prepared and $1950 \mu \mathrm{l}$ of this solution was added to $50 \mu \mathrm{l}$ of various concentrations $(10,100,200,400$ and 500 $\mu \mathrm{g} / \mathrm{ml}$ ) of samples dissolved in methanol to be tested. BHA, ascorbic acid and quercetin, were used as standard. After $1 \mathrm{~h} 30 \mathrm{~min}$, of incubation in a dark room, absorbances were read at $517 \mathrm{~nm}$. The scavenging inhibitory effect of DPPH was calculated according to the following formula: DPPH radical scavenging activity $(\%)=[($ Absorbance of controlAbsorbance of sample)/Absorbance of control] $\times 100$

The concentration of the test extracts providing $50 \%$ inhibition ( $\mathrm{IC}_{50}$, expressed in $\mathrm{ig} / \mathrm{ml}$ ) were calculated from the graph plotted with inhibition percentage against the extracts concentration. All determinations were performed in triplicate.

\section{Antimicrobial activity}

The bacterial cultures used in this study are of clinical origin (isolated and identified by the Service from Bacteriology, Hospital EHU of Oran, Algeria); they are eight bacteria and three fungi strains: Escherichia coli ATCC 25922, pseudomonas aeruginosa ATCC 27853, Klebsilla pneumonia ATCC 13883, Salmonella typhimurium ATCC 13311, Proteus vulgaris ATCC 13315, Bacillus cereus ATCC 14579, Staphylococcus aureus ATCC 25923, Enterococcus faecalis ATCC 29912, Candida albicans ATCC 10231, Aspergillus niger ATCC 16404 and Trichophyton rubrum ATCC 28188.

The anti-microbial activity test, carried out on the various fractions and the extracts of the fruits of $A$. leucotrichus Coss. et al., Dur., was determined using the disk diffusion method ${ }^{12-13}$. Bacteria species were cultivated for $24 \mathrm{~h}$ in Muller Hinton medium $(\mathrm{MHI})$ at $37^{\circ} \mathrm{C}$ and for $48 \mathrm{~h}$ at $25^{\circ} \mathrm{C}$ in Sabouraud medium for fungi. The suspension of the tested microorganisms (approximately $10^{6} \mathrm{CFU} / \mathrm{ml}$ ) was spread on the solid media plates $(20 \mu \mathrm{l})$. A sterile 6-mm-diameter Filter disk (Wattman paper $\mathrm{N}^{\circ} 3$ ) was impregnated with $10 \mu \mathrm{L}$ of serial dilutions in dimethyl sulfoxide (DMSO) of the various fractions and the extracts (EM1, EM2, EE ${ }_{70 \%}$, EED, DMC, and $\mathrm{BOH}$ ), and was placed onto the solid media plates. The diameter of inhibition was measured after 24 or $48 \mathrm{~h}$ of incubation at $25^{\circ} \mathrm{C}$ or $37^{\circ} \mathrm{C}$. Standard antibiotic CN (Céfalexine $10 \mu \mathrm{g}$ ) was used in order to control the sensitivity of the tested bacteria. The antimicrobial activity was assessed by measuring the zone of growth inhibition surrounding the disks.

\section{RESULTS AND DISCUSSION}

Knowledge of phytochemical composition of plants is important in discovery of therapeutic agents for treatment and prevention of various 
diseases. The present work focused essentially on the phytochemical, antioxidant and antibacterial studies from A. leucotricus Coss. et al., Dur. The specie has been screened for 12 chemical groups by reactions colored and results are represented in Table. 1. It is worth noting that the presence of Quinones, Anthracenes compounds, Sterols and triterpenes, Reducing compounds, Phenol acids and Cardiotonic glucoses has not been previously reported in the literature. The presence of such metabolites indicates importance of plant extracts, for examples, flavonoids are considered important due to their antioxidant and antimicrobial activities ${ }^{14}$.

The result of antioxidant activity by the ferric reducing was detected in all the extracts: weak in the aqueous extract, oils essential and strong in the extract methanolic of $A$. leucotrichus fruits. The reducing ability of a compound generally depends on the presence of reductants ${ }^{15}$ which have been exhibiting antioxidative potential by breaking the free radical chain and donating a hydrogen atom ${ }^{16}$. The capacity of the methanolic extract to reduce $\mathrm{Fe}^{+3}$ ions into $\mathrm{Fe}^{+2}$ ions was determined (Fig. 1), this antioxidant activity of methanolic extract weak compared to reference compound (BHT) in 0.25 $\mathrm{mg} / \mathrm{ml}$ to $0.75 \mathrm{mg} / \mathrm{ml}$ concentrations, but starting from $1 \mathrm{mg} / \mathrm{ml}$ concentration, antioxidant activity is much better $(140 \%)$.
All the extracts (methanol, water and essential oil) showed a remarkable quantity of antioxidant activity, although the values were quite less than the references antioxidants (BHA, Ascorbic acid, Quercetin). Free radical scavenging activity of all the extracts and references antioxidants increased with the increase in concentration. The maximum percentage inhibition of DPPH free radical at $517 \mathrm{~nm}$ is exhibited by ascorbic acid about 93.56 to $99.00 \%$; followed by methanol extract, Quercetin, BHA, essential oil and aqueous extract of $A$. leucotrichus as shown in Table. 2.

It is implied that plant extracts contain compounds such as phenols, flavonoids, etc., which can donate hydrogen to a free radical in order to remove odd electron indicating its usefulness in various radical related pathological condition; pattern of inhibition being similar at variable concentration due to the fact that it possesses high radical scavenging activity, that is, this concentration is sufficiently high to scavenge free radicals. Methanol extract of $A$. leucotrichus has shown the highest activity followed by essential oil and water extract. The antioxidant activity shown by methanol extract was much higher than that of oil essential which may be due to the presence of polar compounds like phenols, flavonoids, etc., that are soluble in methanol ${ }^{17}$.

Table. 1: Phytochemical screening by color reactions of $A$. leucotrichus fruits

\begin{tabular}{|c|c|c|}
\hline Compound groups & Tests & Results \\
\hline -Tannin & Stiasny & + \\
\hline -Quinones : Free quinones & $\mathrm{HCl}, 1 \mathrm{~N}, \mathrm{CHCl}_{3}-\mathrm{NH}_{4} \mathrm{OH}$ & - \\
\hline Combined quinones & $\mathrm{H}_{2} \mathrm{SO}_{4}$ reflux $\mathrm{CHCl}_{3}^{4}$ & - \\
\hline -Anthracenes compounds: Free anthracenes & $\mathrm{CHCl}_{3}^{2} / \mathrm{NH}_{4} \mathrm{OH}$ Extract & + \\
\hline Combined anthracenes & $\mathrm{CHCl}_{3}^{3} / \mathrm{FeCl}_{3}^{4}$ Extract & ++ \\
\hline -Sterols and triterpenes & Libermann burchard & +++ \\
\hline -Sesquiterpene lactones & Aqueous extract $/ \mathrm{CHCl}_{3}$ & - \\
\hline -Reducing compounds & Fehling & + \\
\hline \multirow[t]{2}{*}{-Alkaloids } & Extraction in acid medium & - \\
\hline & Extraction in alkaline medium & + \\
\hline -Phenol acids & Folin-Ciocalteu & $\begin{array}{l}\text { Cinnamic acid } \\
\text { Ferulic acid }\end{array}$ \\
\hline -Cardiotonic glucoses & $\mathrm{AcOPb}$ extraction & + \\
\hline -Saponins & $\mathrm{CH}_{2} \mathrm{Cl}_{2}$ extract & +++ \\
\hline -Flavonoids & $\mathrm{MeOH}$ extract & +++ \\
\hline -Coumarins & $\mathrm{MeOH}$ extract & +++ \\
\hline
\end{tabular}

Key: (-) absent; (+): low quantity; (++): average quantity; (+++): high quantity. 


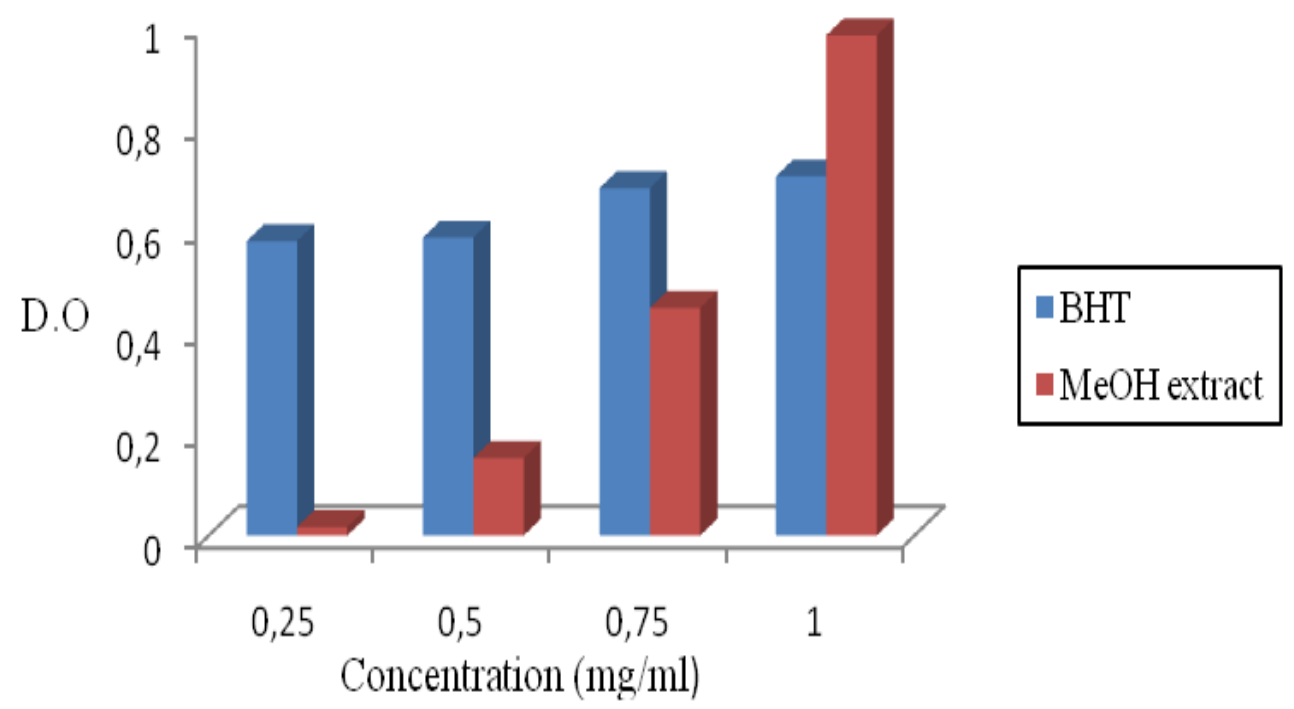

Fig.1: Total reducing power of different concentrations $(0.25-1.0 \mathrm{mg} / \mathrm{ml})$ of methanolic extract and reference antioxidant: BHT

Table. 2: DPPH radical-scavenging activity of $A$. leucotrichus fruits

\begin{tabular}{lccccc}
\hline Samples & \multicolumn{7}{c}{ Pourcentage d'inhibition du radical DPPH $(\%)^{a}$} & & \\
\hline & $10(\mu \mathrm{g} / \mathrm{ml})$ & $100(\mu \mathrm{g} / \mathrm{ml})$ & $200(\mu \mathrm{g} / \mathrm{ml})$ & $400(\mu \mathrm{g} / \mathrm{ml})$ & $500(\mu \mathrm{g} / \mathrm{ml})$ \\
MeOH extract & $4.35 \pm 1.22$ & $50.57 \pm 2.01$ & $89.29 \pm 1.11$ & $93.31 \pm 4.87$ & $98.16 \pm 0.15$ \\
E.Oil & 26.45 & 27.52 & 36.17 & 65.51 & 78.91 \\
A.P extract & $11.22 \pm 0.11$ & $18.31 \pm 0.55$ & $26.89 \pm 2.60$ & $35.47 \pm 0.18$ & $65.18 \pm 1.13$ \\
BHA & $31.18 \pm 1.02$ & $38.11 \pm 4.80$ & $69.30 \pm 1.17$ & $92.07 \pm 0.07$ & $94.88 \pm 0.01$ \\
Ascorbic acid & $25.57 \pm 0.29$ & $40.92 \pm 0.99$ & $93.56 \pm 6.90$ & $99.00 \pm 0.36$ & $99.00 \pm 0.58$ \\
Quercétine & $35.47 \pm 1.28$ & $71.61 \pm 0.62$ & $97.85 \pm 0.22$ & $97.85 \pm 0.54$ & $97.85 \pm 0.95$ \\
\hline
\end{tabular}

a Mean $\pm S D(n=3)$

As shown in Table. 2, antioxidant activity dosing by using DPPH whitening assesses that methanol extract has the best performance, particularly in 500 concentrations where the activity is equivalent to positive indicators: BHA, ascorbic acid and quercetin. $I C_{50}$ value settled for every sample is stated as being the substrate concentration losing $50 \%$ of DPPH activity (Table. 3). Lower $I C_{50}$ value indicates higher antioxidant activity.

All extracts have a free radical reduction capacity. Required concentrations to neutralize and stabilize $50 \%$ of DPPH concentration goes from 2 to $4 \mu \mathrm{g} / \mathrm{ml}$. Comparing results from reference compounds (BHA, Quercetin and Ascorbic acid), we assess that methanol extract activity is quite similar to BHA activity and that extracts antioxidant capacity is decreasingly arranged as follows: Methanol extract $>$ E.oil > Aqueous extract of aerial part.

In this study, we evaluated the antimicrobial activity of the various fractions and extracts of fruits from A. leucotricus Coss. et al., Dur. on the in vitro growth of eight bacterial strains and three fungi strains. As shown in Table. 4, the inhibition zones of disc for strains were in the ranges $7.0-18.0 \mathrm{~mm}$. Generally, the extracts of the plant were moderately active against Gram positive and negative bacteria. This was followed by $\mathrm{DMC}, \mathrm{BOH}$, EEM1, EE ${ }_{70 \%}$, EEM2 and EED extracts respectively. The growth of $E$. coli and $S$. aureus were inhibited by different fractions and extracts. The results against the fungic stocks are interesting (Table. 4), 


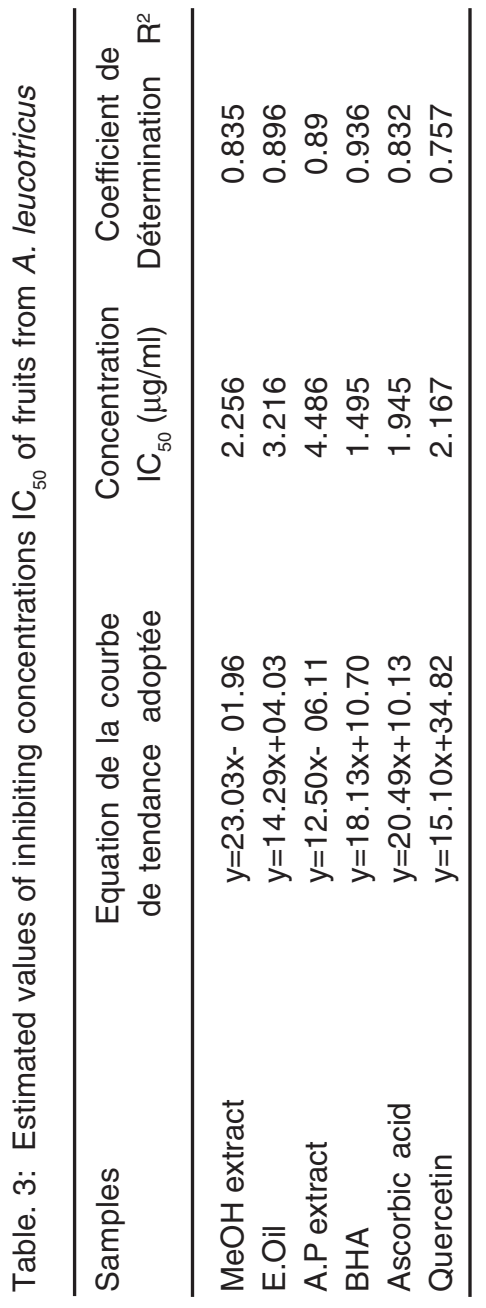

because all the extracts and fractions from $A$. leucotrichus announced a antifungal activity and the greatest effect was obtained by fraction $\mathrm{BOH}$ on T. rubrum and extract EM2 on C. albicans whose zones of inhibition were of 20 and $15 \mathrm{~mm}$ respectively, contrary to $A$. niger only the extract EM2 and fraction $\mathrm{BOH}$ gave an inhibition. When comparing the antibacterial activity of the tested extracts to that of reference antibiotic, Céfalexine, their inhibitory potency was not found to be significant. The maximum antimicrobial activity against $B$. cereus and $T$. rubrum of fractions DMC and $\mathrm{BOH}$ could be explained by the presence of various components, in particular, the flavonoïdes, tannins, the phenolic acids, and terpenes whose antimicrobial properties have been demonstrated by several researchers ${ }^{18-19}$.

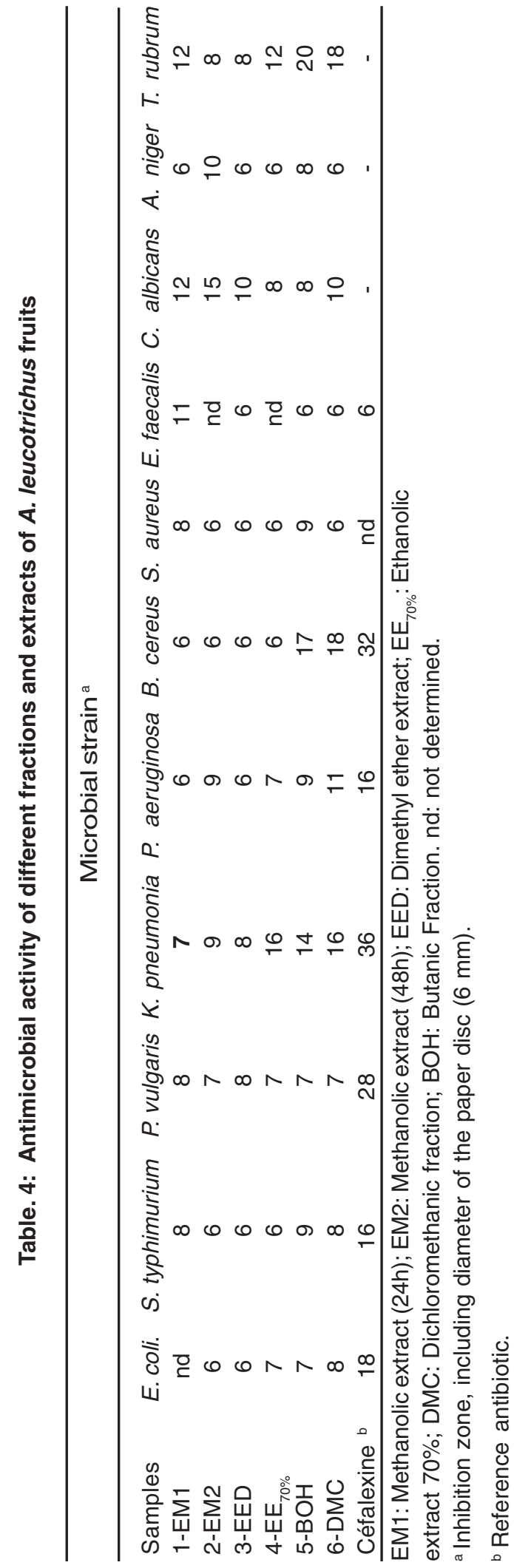




\section{CONCLUSION}

Results are directly related to quantitative and/or qualitative diversity of compounds' content in extracts. It is important to be aware that these results were obtained only in vitro. The interesting fact is that we can then directly study compounds' or extracts' antioxidant activity in vivo to correlate results recorded in both cases. Further studies on other different micro-organisms will help in the evaluation of the therapeutic potential of this plant.
These results of antimicrobial assays justified and supported partly the popular usage of the all parts, especially fruits as traditional remedies for some infections.

\section{ACKNOWLEDGMENT}

The authors wish to thank the Ministry of Higher Education and Scientific Research of Algeria for financial support (Project Cnepru No. E1820130013).

\section{REFERENCES}

1. Ozenda, P. Flore and vegetation of the Sahara. 3th edition, editions of the national center of scientific research, 2004.

2. Bernard, M.; Fouzia, D.; Didler Le, N.; Souad, FT and Jean-Pertte, R. Phytochem, 1997, 44, 907-910.

3. Maberly, P.L. The Plant Book. Cambridge University Press, Cambridge, UK,1998.

4. Quezel, P and Santa, S. Nouvelle flore de l'Algérie et des régions désertiques méridionales. Edition du centre national de la recherche scientifique, 1963.

5. Hammiche, V.; Maiza, K. J. Ethnopharmacol. 2006, 105, 358-367.

6. Velasco-Negueruela, A.; Pérez-Alonso, M.J, Pérez de Paz, P.L.; Palá-Paúl, J and Sanz, J. J. Chromatogr. A. 2006, 1108, 273-275.

7. Fry, S.C. The Growing Plant Cell Wall: Chemical and Metabolic Analysis, Longman scientific and technical, UK, 1988.

8. Wagner, $\mathrm{H}$ and Bladt, S. Plant Drug Analysis: A Thin Layer Chromatography Atlas. Springer-Verlag: Berlin. Heidelberg, New York, 1996.

9. Yen, G. C and Chen, H. Y. J. Agric. Food Chem. 1995, 43, 27-32.

10. Takao, T.; Kitatani, F.; Watanabe, N.; Yagi, A and Sakata, K. Biosci. Biotechnol. Biochem. 1994, 58, 1780-1783

11. Roberto Lo Scalzo. Food Chem. 2008,107, 40-43.

12. Sacchetti, G.; Maietti, S .; Muzzoli, M .; Scaglianti, M.; Manfredini, S .; Radice, M and Bruni ,R. Food Chem. 2005, 91, 621-632.

13. Celiktas, O.Y.; Kocabas, E.E.H.; Bedir, E.; Sukan, F.V.; Ozek, T and Baser, K.H.C. Food Chem. 2007, 100, 553-559.

14. Baydar, H.; Sagdic, O.; Ozkan, G and Karadogan, T. Food Control. 2004, 15, 169-172.

15. Duh, P.D.; Tu, Y.Y and Yen, G.C. Technol. 1999, 32, 269-277.

16. Gordon, M.H. The mechanism of the antioxidant action in vitro, In: Food antioxidants, (ed) B.J.F. Hudson, Elsevier, London. (1990).

17. Bhusal, A.; Jamarkattel, N.; Shrestha, A.; Lamsal, N.K.; Shakya, S.; Rajbhandari, S. J. Clin. Diagn. Res. 2014, 8, HC05.

18. Bisignano, G.; Tomaino, A.; Lo Cascio, R.; Crisafi, G.; Uccella, N and Saija, A. J. Pharm. Pharmacol. 1999, 51, 971- 4.

19. Markin, D.; Duek, L and Berdicevsky, I. Mycoses. 2003, 46, 132-136. 